\title{
EFICIÊNCIA DO ETHEPHON NA UNIFORMIZAÇÃO E ANTECIPAÇÃO DA MATURAÇÃO DE FRUTOS DE CAFEEIRO (Coffea arabica L.) E NA QUALIDADE DA BEBIDA
}

\author{
GLADYSTON RODRIGUES CARVALHO ${ }^{1}$ \\ ANTÔNIO NAZARENO G. MENDES ${ }^{2}$ \\ LUCINE FALCO CARVALHO ${ }^{3}$ \\ GABRIEL FERREIRA BARTHOLO ${ }^{4}$
}

\begin{abstract}
RESUMO - O experimento foi conduzido na Fazenda Experimental da EPAMIG, em Patrocínio, Minas Gerais, com o objetivo de avaliar o efeito do Ethephon na antecipação e uniformização da maturação de frutos de cafeeiro e sua atuação na desfolha do mesmo e na qualidade da bebida. Foram utilizadas três cultivares de cafeeiro (Coffea arabica L.) com diferentes épocas de maturação de frutos (precoce, média e tardia), na presença e ausência de Ethephon, na dosagem de $130 \mathrm{ml}$ do produto comercial por 1001 de água. O delineamento estatístico utilizado foi em blocos casualizados com 4 repetições e 10 plantas por parcela, sendo úteis as 8 centrais. As aplicações foram realizadas quando se obteve índice de frutos no estádio de "cereja" próximo a 30\%, considerando o terço superior, médio e inferior da planta. As características avaliadas foram: porcentagem de frutos no estádio de verde, verde-cana, cereja e seco, no momento da aplicação e em intervalos de 5 dias até a co-
\end{abstract}

lheita, sendo esta realizada quando a porcentagem de frutos verdes foi igual ou menor que 5\%; análise sensorial e química da bebida; classificação do produto final quanto ao tipo e porcentagem de desfolha, em ramos marcados no terço médio das plantas. Pelos resultados obtidos, verifica-se que o uso de Ethephon proporciona uma uniformidade e antecipação de 15 a 30 dias na maturação dos frutos do cafeeiro, mas não interfere na qualidade da bebida e nem na classificação do café, quando comparado com amostras que não receberam o produto e foram colhidas com a mesma porcentagem de café no estádio 'verde' $(<5 \%)$. O Ethephon, quando comparado com a testemunha, promove uma desfolha mais acentuada logo após a sua aplicação; porém, por ocasião da colheita, essa desfolha não é significativa na cultivar Acaiá Cerrado, variando de 3,03 na cultivar Catuaí e de $8,45 \%$ na cultivar Topázio.

TERMOS PARA INDEXAÇÃO: Café, colheita, maturação, qualidade, Coffea arabica.

\section{EFFICIENCY OF ETHEPHON IN THE UNIFORMIZATION AND ANTICIPATION OF THE MATURATION OF COFFEE FRUITS ( Coffea arabica L. ) AND BEVERAGE QUALITY}

\begin{abstract}
The experiment was conducted at the Experimental farm of the EPAMIG in Patrocinio, Minas Gerais, with the objective of evaluating the effect of etephon on the anticipation and uniformization of the coffee fruits maturation verifying, as well as on defoliation and beverage quality. Three cultivars of coffee (Coffea arabica) with different times of fruit maturation (early, medium and late), in the presence and absence of etephon at the rate of $130 \mathrm{ml}$ of the
\end{abstract}

commercial product per $100 \mathrm{~L}$ of water, were utilized. The statistical design utilized was randomized blocks with four replicates and 10 plants per plot. The applications were performed when indices of fruit at the berry stage close to $30 \%$ were obtained, taking into consideration the superior, medium and lower third of the plant. The characteristics evaluated were: percentage of fruit at the green, cane green, berry and dry stages, at the moment of application, and in

1. Pesquisador EPAMIG, Doutorando em Fitotecnia pela UNIVERSIDADE FEDERAL DE LAVRAS/UFLA, Caixa Postal 37 - 37200-000 - Lavras, MG.

2. Professor do Departamento de Agricultura da UFLA.

3. Engenheiro Agrônomo, MS.

4. Pesquisador EPAMIG/CTSM. 
5 day intervals until harvest, this being accomplished when the percentage of fruits was equal to or less than 5\%; chemical and sensorial analysis; the classification of the final product as to the sort and percentage of defoliation branches marked on the medium third of the plants. From the results obtained, it was found that the use of etephon provides both uniformity and anticipation of 15 to 30 days at the maturation of coffee fruits, does not influence either beverage quality or coffee classification when compared with samples which did not receive the product and were harvested with the same percentage of coffee at the green stage $(<5 \%)$. The ethephon, when compared with the check, promotes a more marked defoliation soon after its application but, on the occasion of harvest, this defoliation is not significative in Acaiá Cerrado cultivar, ranging from 3.03 in Catuaí cultivar and from $8.45 \%$ in Topázio cultivar.

INDEX TERMS: Coffee, harvest, maturation, quality, Coffea arabica.

\section{INTRODUÇÃO}

A valorização da qualidade do café já é uma antiga preocupação, levando os setores ligados à atividade cafeeira a elaborar as normas de classificação de café em 1917, (Teixeira, 1972). Nessas normas, que poucas modificações sofreram até hoje, observa-se a ênfase a certos atributos que estão associados à aceitação ou rejeição do café para o consumo.

Segundo Carvalho \& Chalfoun (1985), a qualidade da bebida do café está associada a diversos fatores, destacando-se, entre eles, a composição química do grão, determinada por fatores genéticos, culturais e ambientais. O sabor característico do café é devido à presença e aos teores dos vários constituintes químicos voláteis e não-voláteis, destacando entre eles os ácidos, aldeídos, cetonas, açúcares, proteínas, aminoácidos, ácidos graxos, compostos fenólicos, além da ação de enzimas em alguns desses constituintes, dando como produtos de reações compostos que interferirão no sabor na "prova de xícara". Dentre os compostos orgânicos estudados, especial atenção foi dada à enzima polifenoloxidase (PFO), a qual está correlacionada positivamente com a qualidade da bebida do café. Draeta \& Lima (1976), citados por Chagas (1994), verificaram que a atividade específica da polifenoloxidase é influenciada pela espécie, variedade e maturação do fruto.

Garruti \& Gomes (1961) estudando a influência do estádio de maturação dos grãos na qualidade da bebida do café, observaram que os cafés cerejas (despolpados e não despolpados) mostravam qualidade de bebida (mole) superior aos frutos colhidos verdes e secos na árvore (bebida dura). Isso se justifica, primeiramente, pelo fato de os frutos verdes ainda não apresentarem os teores de alguns componentes químicos em níveis ideais para proporcionar bebida de alta qualidade. Além disso, os grãos secos na árvore, por estarem em um estádio além do ponto cereja (ideal de maturação), entram na fase de senescência, quando, então, ocorrem mudanças fermentativas com produção de compostos químicos indesejáveis ao bom sabor do café.

O uso de Ethephon entra como uma alternativa de produto que objetiva, com a sua aplicação, promover uma maior uniformidade e antecipação da maturação, apresentando, assim, efeitos diretos na cultura. A presença de etileno na planta também faz com que a abscisão dos frutos seja mais fácil, proporcionando uma colheita mais eficiente, com frutos mais uniformes e, conseqüentemente, um produto final de custo mais baixo e com melhor qualidade.

O etileno é produzido em quase todas as células de plantas superiores. As taxas mais altas de produção estão associadas com regiões meristemáticas e os tecidos da região de nós, ao passo que as mais baixas, com os tecidos dos entre-nós. A produção de etileno aumenta em órgãos feridos, folhas e flores cortadas, gemas dormentes, como também durante a senescência e abscisão de tecidos foliares e florais. O nível de etileno aumenta nas flores após a polinização e nos frutos, à medida que amadurecem. Várias substâncias são capazes de liberar etileno por meio de alguma reação química. Dessas, a mais utilizada e efetiva é o ácido 2-Cloroetil-fosfônico, conhecido como Ethrel, Ethephon, ou CEPA (Felipe, 1986).

Ainda segundo o mesmo autor, um agrupamento $-\mathrm{CH}_{2}-\mathrm{CH}_{2}$ no centro da molécula, com um centro removedor de elétrons de um lado e um doador de elétrons no outro, é capaz de produzir etileno. A liberação do etileno em plantas (a partir do Ethephon) não envolve nenhuma atividade enzimática da planta tratada, mas é uma simples reação base-catalisada. O Ethephon é estável em forma ácida, mas libera etileno em $\mathrm{pH}$ acima de 3,5. A taxa de liberação de etileno aumenta à medida que o $\mathrm{pH}$ aumenta. $\mathrm{O}$ Ethephon pode ser translocado por toda a planta. Na uva, ele é mais efetivo quando aplicado na superfície das folhas ou no interior dos frutos. 
$\mathrm{Na}$ cultura do cafeeiro, diversos trabalhos foram realizados com o uso do Ethephon, objetivando antecipar e uniformizar a maturação de frutos; contudo, poucos avanços foram alcançados. Boawning \& Cannel (1970), Rodrigues \& Jordan (1970) e Duarte et. al. (1977), citados por Foloni (2000), verificaram que a aplicação de Ethephon proporcionou uma antecipação na maturação dos frutos quando comparado com cafeeiros que não receberam o produto.

Teixeira et al. (1986), citados por Garcia et. al. (2000), verificaram que não houve melhora na maturação quando as aplicações ocorreram em frutos verdes. $\mathrm{Na}$ aplicação em frutos com $10-20 \%$ de frutos maduros, verificaram alguns resultados e sugeriram novos ensaios.

Recentemente, com a necessidade de obtenção de produtos com melhor qualidade de bebida e com o avanço da mecanização na operação de colheita, novos estudos têm sido realizados com o Ethephon na cultura do cafeeiro.

Foloni (2000), estudando o efeito de duas formulações comerciais de Ethrel (Ethrel 240 e 720), verificou que o Ehrel 240, na dosagem de 1,5 1/ha, e o Etrhel 720, na dosagem de 0,35 1/ha, mostraram-se eficientes na maturação dos grãos de café quando aplicados em cafeeiros com cerca de $10 \%$ de frutoscereja e $90 \%$ de frutos, do terço inferior da planta, já granados.

Quaggio et al. (19--) citado por Garcia et al. (2000), constataram níveis baixos de queda de folhas e frutos quando foi utilizada dosagem inferior a $800 \mathrm{ppm}$ de Ethephon.

Garcia et al. (2000), estudando o efeito do Ethrel 720 na dosagem de $130 \mathrm{ml}$ do produto comercial por 100 litros de água, verificaram que houve um aumento significativo na porcentagem de frutos maduros, quando comparado com cafeeiros não tratados, porém, os resultados de classificação nas amostras revelaram um número muito alto de grãos verdes, o que é conside- rado defeito pela Tabela Oficial de Classificação, o que parece não justificar a aplicação do produto.

Diante disso, objetivou-se com o presente trabalho avaliar o efeito do Ethephon na antecipação e uniformização da maturação de frutos de cafeeiro, verificando sua atuação na desfolha da planta e na qualidade da bebida.

\section{MATERIAL E MÉTODOS}

O experimento foi conduzido na Fazenda Experimental da EPAMIG, em Patrocínio, Minas Gerais. Foram utilizadas três cultivares de cafeeiro (Coffea arabica L.) com diferentes épocas de maturação de frutos: precoce, média e tardia.

Os talhões onde foram instalados os ensaios receberam tratos culturais recomendados para lavoura em produção, sendo realizada adubações de solo e foliar, controle de pragas e doenças, manejo de plantas daninhas, bem como outras atividades que se fizeram necessárias para o bom desenvolvimento da lavoura.

Os tratamentos utilizados foram:

- Cultivares: Acaiá Cerrado MG-1474

Topázio MG-1190

Catuaí Vermelho IAC-15

- Presença e Ausência de Ethephon

$\mathrm{O}$ delineamento estatístico utilizado foi em blocos casualizados com 4 repetições e 10 plantas por parcela, sendo úteis as 8 centrais.

A aplicação do Ethephon foi realizada com equipamento costal motorizado Jacto, sendo utilizada a dosagem de $130 \mathrm{ml}$ do produto comercial por $100 \mathrm{li}$ tros de água, com volume de calda definido com base na idade da lavoura e no espaçamento, de modo a proporcionar boa cobertura de folhas e frutos (Quadro 1).

As aplicações foram realizadas quando obteve-se índice de frutos no estádio de "cereja” próximo a 30\%, considerando o terço superior, médio e inferior da planta. Para isso, coletaram-se, semanalmente, amostras de

QUADRO 1 - Caracterização dos talhões e volume de calda utilizado em cada cultivar.

\begin{tabular}{|l|c|c|c|c|}
\hline \multicolumn{1}{|c|}{ Cultivares } & Plantio & Espaçamento & Vol. de calda/parcela & Vol. de calda/ha \\
\hline Acaiá Cerrado MG-1474 & Jan./95 & $4,0 \times 1,00 \mathrm{~m}$ & 2,80 litros & 700 litros \\
\hline Topázio MG-1190 & Fev./97 & $3,5 \times 0,70 \mathrm{~m}$ & 2,32 litros & 950 litros \\
\hline Catuaí Vermelho IAC-15 & Jan./97 & $4,0 \times 0,70 \mathrm{~m}$ & 2,37 litros & 850 litros \\
\hline
\end{tabular}

Ciênc. agrotec., Lavras. V.27, n.1, p.98-106, jan./fev., 2003 
frutos, dentro das parcelas, em cada cultivar, até obtenção da porcentagem desejada para a aplicação do produto.

As características avaliadas foram:

a) Porcentagem de frutos no estádio verde, verdecana, cereja e seco, no momento da aplicação e em intervalos de 5 dias até a colheita, sendo essa realizada quando a porcentagem de frutos verdes foi igual ou menor que 5\% . Foram coletados frutos no terço superior, médio e inferior das plantas, misturados e a partir da amostra composta, retirou-se 0,5 litro de café para contagem e determinação do índice de maturação. Por ocasião da colheita, retirou-se de cada parcela uma amostra de 5 litros de café da roça, o qual foi seco para as avaliações de qualidade.

b) Porcentagem de desfolha, em ramos marcados no terço médio das plantas. Nessa avaliação, foram marcados aleatoriamente 4 ramos por planta nas 4 centrais e contados o número de folhas por ramo no ato da aplicação; a partir daí, foram realizadas avaliações em intervalos de 5 dias até a colheita,determinando-se a porcentagem de desfolha.

c) Análise sensorial da bebida ("Prova de xícara") - Foram retiradas amostras de 300 gramas de café beneficiado de cada tratamento e enviadas a 4 provadores (EPAMIG e Cooperativas).

d) Análise química da bebida - pelo índice de coloração, compostos fenólicos totais, açúcares totais, açúcares redutores e não-redutores, acidez titulável total e atividade da enzima polifenoloxidade.

e) Classificação do produto final quanto ao tipo, seguindo padrão usual e considerando a contagem do número de defeitos por amostra.
Para a determinação das análises qualitativas, foram tomadas amostras de 4 litros de café "da roça", secos em peneiras e encaminhados ao Laboratório de Qualidade "Dr. Alcides de Carvalho", em Lavras, Minas Gerais.

Os dados obtidos foram analisados estatisticamente, pelo Teste de Tuckey, a 5\% de significância, pelo teste $\mathrm{F}$.

\section{RESULTADOS E DISCUSSÃO}

Pela análise de variância, verificou-se para as características de porcentagem de frutos "verde", "cereja" e "seco", em todas as cultivares, que houve efeito significativo pelo teste $\mathrm{F}$ para os fatores presença e ausência de Ethephon e época de avaliação, bem como para a interação entre eles. Já, para a característica porcentagem de frutos "verde cana", houve efeito significativo pelo teste $\mathrm{F}$, para o fator presença e ausência de Ethephon, apenas na cultivar Catuaí Vermelho IAC-15, o que pode ser explicado pela desuniformidade de maturação que a mesma apresenta.

Analisando a Figura 1, observa-se que, após a aplicação de Ethephon, houve uma redução na porcentagem de frutos no estádio verde, em um curto espaço de tempo para as três cultivares, e as mesmas atingiram a porcentagem de frutos "verdes" desejável por ocasião da colheita $(<5 \%)$, com 20,25 e 35 dias após a aplicação do produto para 'Acaiá Cerrado', 'Topázio' e 'Catuaí Vermelho IAC-15', respectivamente.
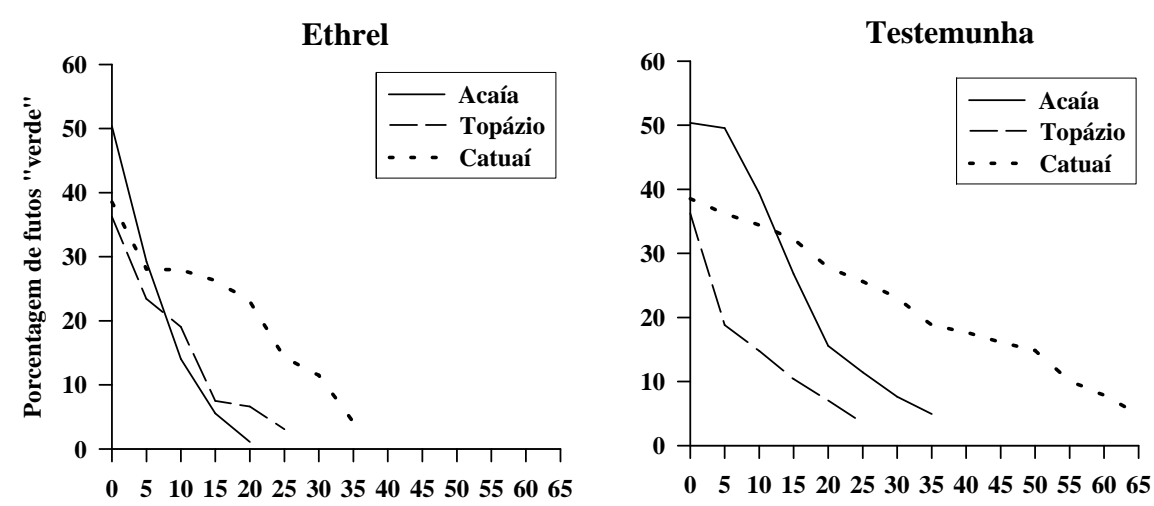

Época de avaliação (dias)

FIGURA 1 - Porcentagem de frutos "verdes", na presença e ausência de Ethephon, avaliada em intervalos de 5 dias até a colheita, para as cultivares Acaiá Cerrado MG-1474, Topázio MG-1190 e Catuaí Vermelho IAC-15. Patrocínio, MG. 2000. 
$\mathrm{Na}$ ausência de aplicação do produto (Testemunha), as cultivares seguiram a maturação natural do cafeeiro, com o mesmo índice de "frutos verdes", para se realizar a colheita somente sendo obtido aos 35, 25 e 65 dias, respectivamente. Com isso, pode-se observar que houve uma antecipação na colheita de 15 dias para a Cultivar Acaiá Cerrado e de 30 dias para a Cultivar Catuaí IAC-15, corroborando afirmações de Foloni (2000), que verificou antecipação na maturação de frutos submetidos à aplicação do Ethephon. Já para a cultivar Topázio, a porcentagem de frutos verdes ideal para se realizar a colheita foi obtida aos 25 dias após o início do experimento, tanto para a área que recebeu o produto quanto para a testemunha.

Com relação à porcentagem de frutos "verdecana", verifica-se, pela Figura 2, resultados semelhantes aos obtidos para a porcentagem de frutos "verdes", ou seja, o tratamento que recebeu a aplicação de Ethephon passou de "verde" para "cereja", estádio "verde-cana", mais rapidamente que a testemunha.

Nesse caso, a antecipação mais expressiva foi para a cultivar Catuaí IAC-15, que novamente apresentou uma antecipação de 30 dias, o que pode ser explicado pelo fato de essa cultivar apresentar, como característica agronômica, uma maturação tardia e desuniforme.

Quando se analisou a porcentagem de frutos no estádio "cereja", que é quando a planta apresenta sua maturação fisiológica completa, que é o estádio ideal para se conseguir cafés de melhor qualidade, a aplicação do Ethephon, mais uma vez, foi favorável e apresentou o mesmo desempenho das outras características para as cultivares estudadas, conforme mostra a Figura 3.

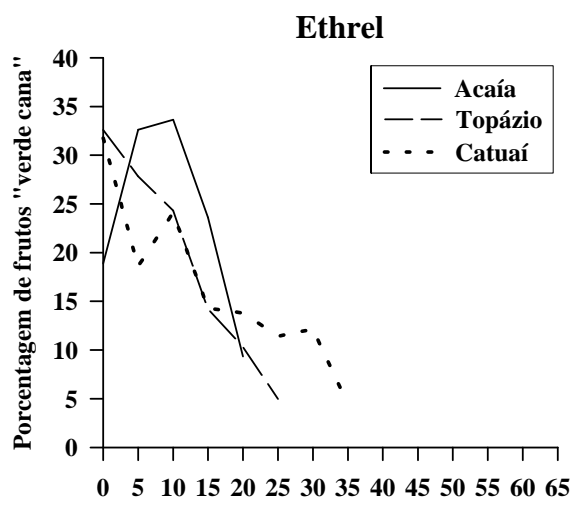

Observa-se que a porcentagem de frutos "cereja", por ocasião da colheita, para a Cultivar Acaiá Cerrado, foi de 86,8\% na área tratada com Ethephon e de 64\% na testemunha, indicando um aumento de aproximadamente $22 \%$ dos frutos no estádio "cereja". Resultado semelhante também foi obtido para a cultivar Catuaí Vermelho IAC15, uma vez que a porcentagem de frutos-cereja na área tratada com Ethephon foi de $88,05 \%$ e na testemunha foi de $66,28 \%$. Esses resultados confirmam relatos de Broawning \& Cannel (1970), Rodrigues \& Jardan (1970) e Duarte et al. (1977), citados por Foloni (2000), que verificaram a antecipação na maturação de frutos de cafeeiros que receberam o produto quando comparados com cafeeiros não-tratados. Já, para a Cultivar Topázio, a aplicação de Ethephon não apresentou diferença nem para época de colheita, nem para porcentagem de frutos "cereja".

Observa-se pela Figura 4 que a porcentagem de frutos no estádio "seco" para as cultivares Acaiá Cerrado e Catuaí Vermelho IAC-15, por ocasião da colheita, no tratamento com Ethephon, foi de 2,70\% e 3,32\%, respectivamente, ao passo que, na Testemunha, foi de $8,50 \%$ e $8,02 \%$. Isso pode ser explicado pela desuniformidade de maturação que ocorre em condições naturais de amadurecimento. Sendo assim, os frutos que tiveram sua maturação antecipada em razão de diversos fatores (época da florada e posição na planta, dentre outros), na época da colheita, já encontravam-se no estádio "seco". Porém, no tratamento com Ethephon, como houve uma uniformização da maturação, um menor número de frutos secos foi obtido, condição essa que, segundo Garruti \& Gomes (1961), é extremamente desejável quando se quer obter uma melhor qualidade de bebida.

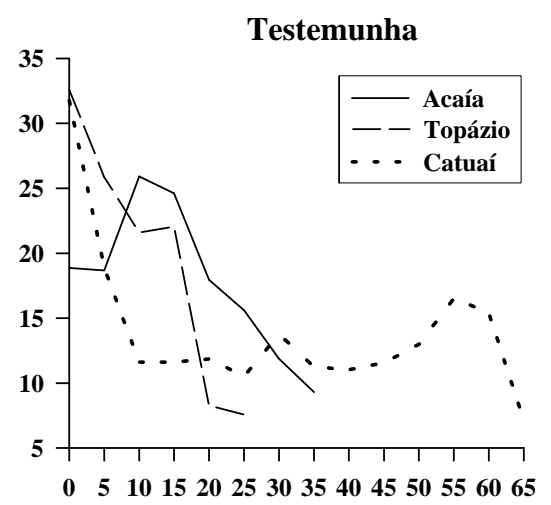

Época de avaliação (dias)

FIGURA 2 - Porcentagem de frutos "verde cana", na presença e ausência de Ethephon, avaliada em intervalos de 5 dias até a colheita, para as cultivares Acaiá Cerrado MG-1474, Topázio MG-1190 e Catuaí Vermelho IAC-15. Patrocínio, MG. 2000. 

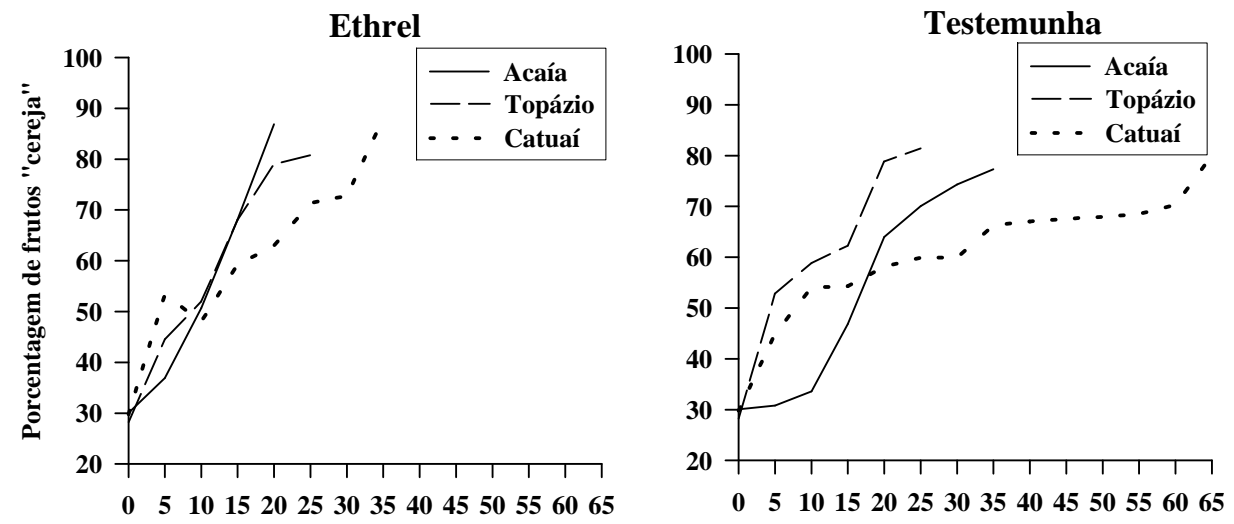

Época de avaliação (dias)

FIGURA 3 - Porcentagem de frutos "cereja", na presença e ausência de Ethephon, avaliada em intervalos de 5 dias até a colheita, para as cultivares Acaiá Cerrado MG-1474, Topázio MG-1190 e Catuaí Vermelho IAC-15. Patrocínio, MG. 2000.
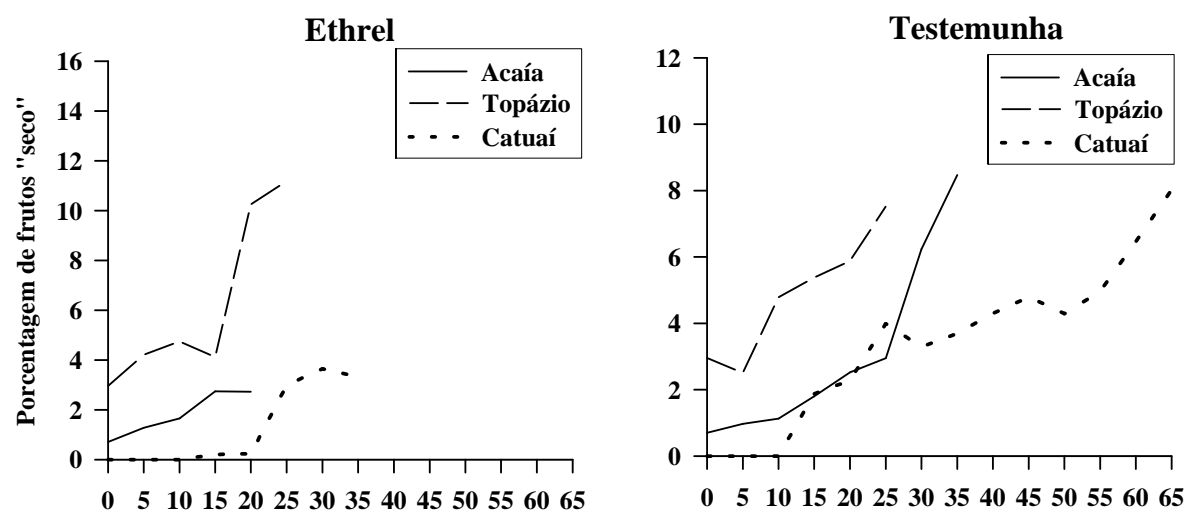

Época de avaliação (dias)

FIGURA 4 - Porcentagem de frutos "seco", na presença e ausência de Ethephon, avaliada em intervalos de 5 dias até a colheita, para as cultivares Acaiá Cerrado MG-1474, Topázio MG-1190 e Catuaí Vermelho IAC-15. Patrocínio, MG. 2000.

Esses autores, estudando a influência do estádio de maturação dos grãos na qualidade da bebida do café, observaram que os grãos secos na árvore, por estarem em estádio além do ponto cereja (ideal de maturação), entram na fase de senescência, quando, então, ocorrem mudanças fermentativas, com produção de compostos químicos indesejáveis ao bom sabor do café.

Com relação à porcentagem de desfolha nas diferentes épocas de avaliação, verifica-se pela Figura 5 que, para todas as cultivares estudadas, a desfolha na presença de Ethephon ocorreu de forma mais rápida.
O Ethephon, por ser um precursor de hormônio, que também está ligado à senescência das folhas, promoveu uma antecipação na queda das mesmas, quando comparado com a testemunha, confirmando afirmações de Felipe (1986).

Quanto à desfolha por ocasião da colheita, houve diferença significativa para cultivares, tratamentos e interação cultivar $\mathrm{x}$ tratamento.

Verifica-se pela Figura 6 que, para a Cultivar Acaiá Cerrado, a desfolha ocorrida por ocasião da colheita foi estatisticamente igual, tanto na presença 
quanto na ausência do Ethephon. Já para as cultivares Topázio MG 1190 e Catuaí Vermelho IAC-15, os tratamentos que receberam a aplicação do produto apresentaram uma desfolha superior à da testemunha. Segundo Quaggio et al. (19--), citados por Garcia (2000), a aplicação de Ethrel em dosagens inferiores a 800 ppm do produto causaram baixos níveis de queda de frutos e de folhas.

A qualidade do café acha-se estreitamente relacionada aos diversos constituintes físico-químicos e químicos responsáveis pelo sabor e aroma característicos das bebidas. Por isso, foi feita a análise de amostras de café para se estudar os seus constituintes e detectar se o uso de Ethephon influencia na qualidade final do café, uma vez que esse produto acelera a maturação do grão.

Para as características Atividade da Polifenoloxidase, Fenólicos Totais, Acidez Titulável Total e Classificação quanto ao Tipo, verificou-se pela análise de variância, que houve diferença significativa pelo Teste $\mathrm{F}$ para o fator cultivar. Para Fenólicos Totais, detectou-se também efeito significativo para a interação cultivares $\mathrm{x}$ tratamentos.

Na Tabela 1 encontram-se os valores médios da Atividade da Polifenoloxidase, Fenólicos Totais, Acidez Titulável Total e Classificação quanto ao Tipo, em função de diferentes cultivares de Cafeeiro.
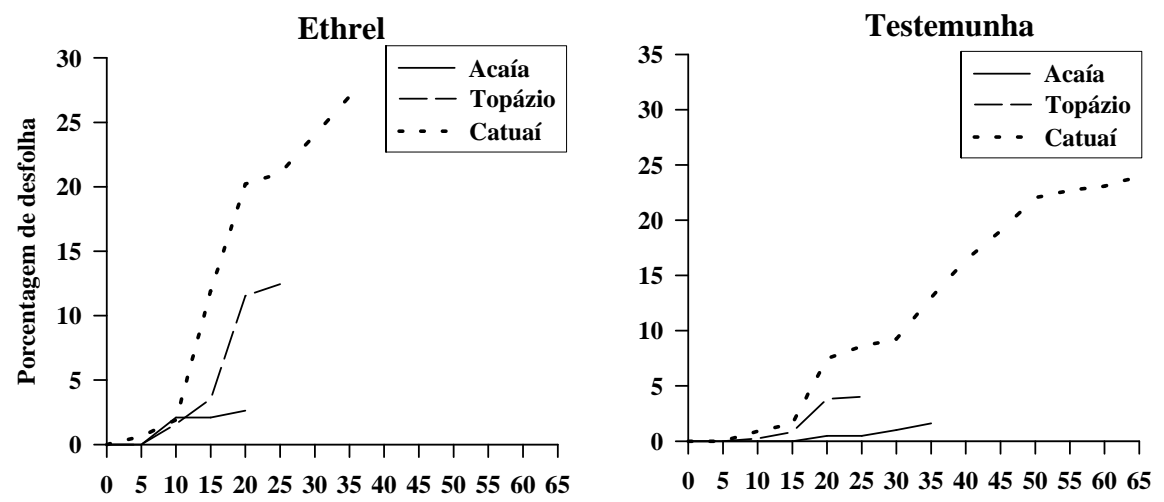

Época de avaliação (dias)

FIGURA 5 - Porcentagem de desfolha, na presença e ausência de Ethephon, avaliada em intervalos de 5 dias até a colheita, para as cultivares Acaiá Cerrado MG-1474, Topázio MG-1190 e Catuaí Vermelho IAC-15. Patrocínio, MG. 2000.

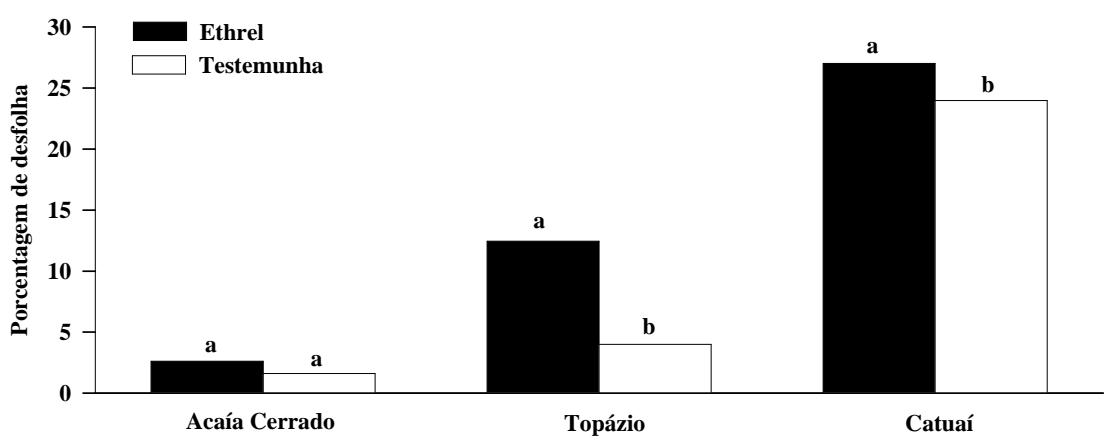

FIGURA 6 - Porcentagem de desfolha, na presença e ausência de Ethephon, avaliada por ocasião da colheita, para as cultivares Acaiá Cerrado MG-1474, Topázio MG-1190 e Catuaí Vermelho IAC-15. 
A enzima Polifenoloxidase (PFO) está correlacionada positivamente com a qualidade da bebida do café, ao contrário do que ocorre com os Fenólicos Totais e a Acidez Titulável Total. Diante disso, a Cultivar Catuaí Vermelho IAC-15 apresentou qualidade de bebida superior às demais, porém, independente do uso do Ethephon, uma vez que não houve diferença significativa para tratamento em nenhuma das características.

Quanto à classificação do café por Tipo, também houve diferença significativa apenas para cultivar, indicando para a Cultivar Acaiá Cerrado um menor número de defeitos, com uma classificação de café Tipo 3, ao passo que para as demais cultivares, obteve-se um café de Tipo 5. Esses resultados discordam dos obtidos por Garcia et al (2000), que encontraram um número elevado de defeitos verdes na amostra tratada com o produto, sugerindo que a maturação poderia estar ocorrendo apenas no exocarpo. Contudo, pelos resultados obtidos neste trabalho verifica-se que a maturação antecipada, provocada pelo uso do produto, não promove apenas a maturação do exocarpo (casca), mas também a completa maturação fisiológica do grão, não prejudicando, entretanto, a qualidade da bebida.
Para as características Índice de coloração, nãoredutores e totais, observou-se pela análise de variância efeito significativo apenas para cultivar, ao passo que, para Açúcares redutores, houve efeito significativo para a interação cultivar $\mathrm{x}$ tratamento.

Analisando a Tabela 2, verifica-se tendência de superioridade para a Cultivar Catuaí Vermelho IAC15 , uma vez que quanto maior os valores dessas características, melhor a qualidade da bebida, confirmando resultados obtidos pela característica atividade da PFO.

Pela Tabela 3, pode-se observar, mais uma vez, que o uso de Ethephon não influenciou negativamente na qualidade da bebida, quando comparado com a testemunha, uma vez que o mesmo ainda causou um maior teor de açúcares redutores e, segundo Chagas (1994), o amadurecimento normal dos frutos promove maiores teores de açúcares redutores e não-redutores e, conseqüentemente, melhor qualidade de bebida.

Pela Tabela 4 confirma-se, mediante interação cultivar $\mathrm{x}$ tratamento, que tanto na presença quanto na ausência de Ethephon, a cultivar Catuaí Vermelho IAC15 apresentou melhor qualidade de bebida.

TABELA 1 - Valores médios da Atividade da Polifenoloxidase ( $\mu / \mathrm{min} / \mathrm{g})$, Fenólicos Totais, Acidez Titulável Total e Classificação quanto ao Tipo, em função de diferentes cultivares de Cafeeiro. Patrocínio, MG. 2000.

\begin{tabular}{|c|c|c|c|c|}
\hline Tratamentos & Atividade de PFO & Fenólicos Totais & Ac. Titulável Total & Classif. Qto Tipo \\
\hline Catuaí Vermelho IAC-15 & $65,73 \mathrm{a}$ & 5,86 a & $200,00 \mathrm{a}$ & $5 \mathrm{~b}$ \\
\hline Topázio MG-1190 & $62,70 \quad b$ & $6,01 \quad b$ & $218,75 \quad b$ & $5 \mathrm{~b}$ \\
\hline Acaiá Cerrado MG-1474 & 60,95 & 6,63 & $221,87 \quad b$ & $3 \mathrm{a}$ \\
\hline
\end{tabular}

- Médias seguidas por letras distintas diferem entre si pelo Teste de Tuckey, a $5 \%$ de probabilidade.

TABELA 2 - Valores médios do Índice de Coloração, Açúcares redutores, não-redutores e Totais nas diferentes cultivares de Cafeeiro. Patrocínio, MG. 2000.

\begin{tabular}{lcccccc}
\hline \multicolumn{1}{c}{ Tratamentos } & Índice de Coloração & Açúcares redutores & Aç. Não redutores & Açúcares Totais \\
\hline Catuaí Verm. IAC-15 & $1,79 \mathrm{a}$ & $0,58 \mathrm{a}$ & $5,84 \mathrm{ab}$ & $6,73 \mathrm{a}$ \\
Topázio MG-1190 & $1,67 \mathrm{~b}$ & 0,27 & $\mathrm{c}$ & $6,06 \mathrm{a}$ & $6,66 \mathrm{ab}$ & \\
Acaiá Cer. MG-1474 & $1,75 \mathrm{a}$ & 0,36 & $\mathrm{~b}$ & $5,65 \mathrm{~b}$ & 6,31 & $\mathrm{~b}$ \\
\hline
\end{tabular}

- Médias seguidas por letras distintas diferem entre si pelo Teste de Tuckey, a 1\% de probabilidade. 
TABELA 3 - Valores médios do Índice de Coloração, Açúcares redutores, não-redutores e Totais de amostras de café beneficiado, na presença e ausência de Ethephon.

\begin{tabular}{lccccc}
\hline \multicolumn{1}{c}{ Tratamentos } & Índice de Coloração & Açúcares redutores & Aç. Não redutores & Açúcares Totais \\
\hline Ethephon & $1,73 \mathrm{a}$ & $0,43 \mathrm{a}$ & $5,79 \mathrm{a}$ & $6,54 \mathrm{a}$ \\
Testemunha & $1,74 \mathrm{a}$ & $0,37 \quad \mathrm{~b}$ & $5,91 \mathrm{a}$ & $6,60 \mathrm{a}$ & \\
\hline
\end{tabular}

- Médias seguidas por letras distintas diferem entre si pelo Teste de Tuckey, a $1 \%$ de probabilidade.

TABELA 4 - Valores médios para açúcares redutores nas diferentes cultivares de Cafeeiro.

\begin{tabular}{lcccc}
\multicolumn{1}{c}{ Tratamentos } & Ethephon & Testemunha \\
\hline Catuaí Vermelho IAC-15 & 0,6275 & $\mathrm{a}$ & 0,5325 & $\mathrm{a}$ \\
Topázio MG-1190 & 0,2075 & $\mathrm{c}$ & 0,3500 & $\mathrm{~b}$ \\
Acaiá Cerrado MG-1474 & 0,4725 & $\mathrm{~b}$ & 0,2500 & $\mathrm{c}$ \\
\hline
\end{tabular}

- Médias seguidas por letras distintas diferem entre si pelo Teste de Tuckey, a 1\% de probabilidade.

\section{CONCLUSÕES}

Pelos resultados obtidos nas condições experimentais do presente ano, pode-se concluir que o uso de Ethephon:

a) Proporciona uma antecipação e uniformidade na maturação dos frutos do cafeeiro;

b) Promove uma antecipação na colheita do café de 15 dias para a Cultivar Acaiá Cerrado MG 1474 e de 30 dias para a Cultivar Catuaí Vermelho IAC-15;

c) Promove uma desfolha mais acentuada logo após a sua aplicação; porém, por ocasião da colheita, essa desfolha não é significativa na cultivar Acaiá Cerrado, variando de 3,03 na cultivar Catuaí e de 8,45\% na cultivar Topázio.

d) Não interfere na qualidade da bebida e nem na classificação do café, quando comparado com amostras que não receberam o produto e foram colhidas com a mesma porcentagem de café no estádio 'verde' $(<5 \%)$.

\section{REFERÊNCIAS BIBLIOGRÁFICAS}

CARVALHO, V. D. de; CHALFOUN, S. M. Aspectos qualitativos do café. Informe Agropecuário, Belo Horizonte, v. 11, n. 126, p. 79-92, 1985.

CHAGAS, S. J. de R. Caracterização química e qualitativa de cafés de alguns municípios de três regiões produtoras de Minas Gerais. 1994. 83 p. Disserta- ção (Mestrado em Ciência dos Alimentos) - Escola Superior de Agricultura de Lavras, Lavras.

FELIPE, G. M. Etileno. In: Fisiologia vegetal 2. 2. ed. São Paulo: EPU, 1986. p. 163-192.

FOLONI, L. L. Avaliação da eficiência de duas formulações de Ethephon (Ehrel 240 e Ethrel 720) em pré colheita do café In: CONGRESSO BRASILEIRO DE PESQUISAS CAFEEIRAS, 26., 2000, Marília. Resumos... Rio de Janeiro: MAA/PROCAFE, 2000. p. 193194.

GARCIA, A. W. R.; TEIXEIRA, A. A.; JAPIASSÚ, L. B.; FROTA, L. B.; FERREIRA, R. A. In: CONGRESSO BRASILEIRO DE PESQUISAS CAFEEIRAS, 26., 2000, Marília. Resumos... Rio de Janeiro: MAA/PROCAFE, 2000. p. 295-297.

GARRUTI, R. S.; GOMES, A. G. Influência do estádio de maturação sobre a qualidade da bebida do café na região do Vale do Paraíba. Bragantia, Campinas, v. 20, p. 989-995, 1961.

TEIXEIRA, A. A. A técnica experimental da degustação do café. 1972.80 p. Tese (Doutorado em Fitotecnia) - Escola Superior de Agricultura "Luiz de Queiróz, Piracicaba. 